\title{
Global Spatial Linkage and China's Economic Growth
}

\author{
Liu Ruixiang ${ }^{1}$, Fan Jin ${ }^{2,}$, Yan Yingen ${ }^{1}$ \\ ${ }^{1}$ Political and Economic Research Institute, Nanjing Audit University, Nanjing, China \\ ${ }^{2}$ Economic Development Research Center, Nanjing Forestry University, Nanjing, China
}

Email address:

ruixiangliu_nj@163.com (Liu Ruixiang),jfan@njfu.edu.cn (Fan Jin), yyg1981@163.com (Yan Yingen)

${ }^{*}$ Corresponding author

\section{To cite this article:}

Liu Ruixiang, Fan Jin, Yan Yingen. Global Spatial Linkage and China's Economic Growth. International Journal of Business and Economics Research. Vol. 7, No. 3, 2018, pp. 42-54. doi: 10.11648/j.ijber.20180703.11

Received: May 21, 2018; Accepted: June 14, 2018; Published: July 11, 2018

\begin{abstract}
In this paper, the sources of China's economic growth are decomposed from the perspective of global linkage. The conclusions include: (1) During the period of analysis, the forward linkage degree of China's economy increased while the backward linkage degree had not been promoted effectively; (2) China's economic dependence on Asia areas declined, while its dependence on North American and development countries increased. (3) In the past twenty years, the rapid growth of China's economy is the result of both internal and external factors. The positive impact of the changes in the global input-output structure on China's economy is mostly short-term and temporary. Finally, this paper puts forward the pertinent policy suggestions.
\end{abstract}

Keywords: China's Economic Growth, Global Linkage, Middle-Income Stage

\section{Introduction}

What is the driving force for economic growth in a country or region? This is an eternal topic in the economics profession. Over the past 40 years of reform and opening up, China's economy has achieved remarkable achievements which is called "growth miracles" in the world. However, after more than 30 years of rapid growth, China's economy began to decelerate obviously since 2012 . The growth rate of GDP declined from $9.5 \%$ in 2011 to $6.7 \%$ in 2016 , causing widespread concern in the world. It is widely believed that a country's development mechanism from middle income to high income is fundamentally different from the mechanism of taking off. Therefore, it is of great theoretical and practical significance to reexamine the dynamic mechanism of economic growth and its evolutionary path of China at this critical moment.

For a long time, when analyzing the source of economic growth in a country or region, economists generally followed Solow's growth accounting framework [1], and decomposed economic growth into factor input and total factor productivity from the perspective of supply [2]. Different from the above, some scholars studied the source of China's economic growth from the perspective of final demand. Shen Lisheng (2009) used the input-output method to calculate the pulling effect of consumption, investment and export as "three carriages" on China's economic production. It is considered that the pulling effect of consumption had been declined since 2002 and the pulling effect of export was rising. Therefore, the pulling effect of consumption must be expanded [3]. Liu Ruixiang and An Tongliang constructed a growth accounting framework based on final demand, analyzed the dynamics of China's economic growth from 1987 to 2007, and found that the growth of China's economic growth was mainly driven by the final demand, but the process of globalization had a fundamental influence on its driving mechanism [4].

Through the above review of literature, it can be found that under the existing growth accounting framework, whether it is based on the supply perspective or the demand perspective, the common ground is to attribute economic growth to its own internal factors, while ignoring a basic fact: In the context of global economic integration, multinational corporations integrated the production resources scattered around the world according to the resource endowments and comparative advantages of countries or regions, and reconfigure the various processes in the production process in different countries or regions, eventually forming an international vertical specialization system. Under this system, countries or regions formed a global production network through the trade in intermediate products, creating technical linkages and 
associated effects with each other. Under the international division of labor system, the economic growth of a country or region depends not only on its own final demand and production technology, but also on the international division of labor system and the position of the country in the global value chain. Therefore, in order to analyze the source of China's economic growth in the context of global integration, it is necessary to consider the impact of the spatial association of countries in the world.

In fact, some literature has used measurement tools to examine the relationship between spatial spillover and economic growth. It has been found that with the significant characteristics of spatial aggregation in China, the spatial spillover effect has exerted an important influence on regional economic development. From the perspective of existing research methods, methods for measuring spatial spillovers mainly include spatial measurement [5] and VAR model [6]. However, the above research methods focus more on the spatial linkage between China's regions and ignore the economic links between China and other countries. In addition, the above research methods can not observe the feedback effect between different regions, and can not reflect the division and cooperation between different regions in the production process. In comparison, the multi-regional input-output approach can not only examine the spillover effect and feedback effect between regions, but also can analyze the inter-regional cooperation in division of labor by means of the intermediate input matrix. Therefore, when studying the spillover effect between regions, people are increasingly investing in multi-regional input-output methods.

Due to the limited availability of data received, early scholars mainly used Asian input-output data to study the economic spatial association between countries in East Asia [7, 8], and only a few literature used the input-output table of China's regions to study the technology spillovers and feedback effects of domestic regions [9]. In recent years, with the increase in global value-added trade research, the international input-output database including WTOD and GTAP has been continuously improved. Timmer et al. decomposed the global value chain and found that the share of capital and highly-skilled laborers in the global value chain increased, but countries at different development stages differed from each other [10]. Wang et al proposed a framework to decompose production activities to different types depending on whether they for pure final demand, traditional international trade, simple GVC activities and complex GVC activities [11]. Although the above literature studies the impact of globalization on value-added trade or industrial structure change, no scholars have used input-output methods to conduct in-depth research on the driving forces behind China's rapid economic growth based on the perspective of global spatial linkage.

Compared with the existing literature, the innovation of this paper includes: (1) Using a multi-regional input-output model to analyze the driving force of China's economic growth from the perspective of global spatial linkage, and it provides a new explanation for China's rapid economic growth; (2) A new growth accounting framework is constructed, which decomposes the economic growth into the value-added rate effect, the domestic multiplier effect, the feedback effect, the external spillover effect and the domestic and foreign demand effect, and understands the driving mechanism behind China's economic growth from different perspectives again; (3) Based on the global input-output model, a series of indicators such as international division of labor, induction and self dependence are defined, and more accurate results are given for the global economic spatial linkage.

The paper is organized as follows: Section 1, introduction; Section 2 presents the theoretical model and data sources; Section 3 analyzes the spatial relationship of the global economy; Section 4 decomposes the source of China's economic growth from the perspective of global spatial linkage; Finally, the last section provides some concluding remarks.

\section{Model and Data Source}

\subsection{The Global Input-Output Model and Measurement of Economic Linkage}

In the global input-output model, the economic interaction of all countries in the world is considered as a whole. Therefore, compared with the single region model, the multi-regional input-output model contains more spatial linkage information. In order to reflect its characteristics more clearly, a simple form of the global input-output model is given as follows:

Table 1. Summary of global input-output model.

\begin{tabular}{|c|c|c|c|c|c|c|c|}
\hline & \multicolumn{3}{|c|}{ Intermediate Use } & \multicolumn{3}{|l|}{ Final Use } & \multirow{2}{*}{ Total Output } \\
\hline & Country 1 & $\ldots$ & Country n & Country 1 & $\ldots$ & Country n & \\
\hline Country 1 & $\mathrm{z}_{11}$ & $\ldots$ & $\mathrm{Z}_{\mathrm{ln}}$ & $f_{11}$ & $\ldots$ & $f_{1 n}$ & $\mathrm{y}_{1}$ \\
\hline$\ldots$ & $\ldots$ & $\mathrm{Z}_{\mathrm{rs}}$ & $\ldots$ & $\ldots$ & $\mathrm{f}_{\mathrm{rs}}$ & $\ldots$ & $\ldots$ \\
\hline Country n & $\mathrm{z}_{\mathrm{n} 1}$ & $\ldots$ & $\mathrm{Z}_{\mathrm{nn}}$ & $f_{n 1}$ & $\ldots$ & $f_{\mathrm{nn}}$ & $\mathrm{y}_{\mathrm{n}}$ \\
\hline Added Value & $\mathrm{v}_{1}$ & $\ldots$ & $\mathrm{V}_{\mathrm{n}}$ & & & & \\
\hline Total Input & $\mathrm{y}_{1}$ & $\ldots$ & $\mathrm{y}_{\mathrm{n}}$ & & & & \\
\hline
\end{tabular}

In the above table, the global input-output model is composed of $n$ countries. The element $z_{\mathrm{rs}}$ in the table indicates the number of intermediate inputs provided by country $r$ to country s. The added value is expressed in $\mathrm{v}$. The total output is equal to the total input and is represented as y. The final product is denoted by $f$, and the corresponding vector (matrix) is expressed in the corresponding capital letters.

According to the balance relationship in the horizontal 
direction of the table, the intermediate product consumption matrix $\mathrm{Z}$ is represented as the multiplication form of the intermediate consumption coefficient matrix $A$ and the total output vector $\mathrm{Y}$, and the following can be obtained:

$$
\mathrm{AY}+\mathrm{F}=\mathrm{Y}
$$

Further deformation of formula (1) can be obtained:

$$
\mathrm{Y}=(\mathrm{I}-\mathrm{A})^{-1} \mathrm{~F}
$$

In the above formula, $\mathrm{B}=(\mathrm{I}-\mathrm{A})^{-1}$ is the complete consumption coefficient matrix, which is known as the Leontief inverse matrix. Similar to the traditional input-output model, in the global input-output model, two indicators are used to describe the economic spatial linkage structure of countries of the world based on the perspective of output value:

$$
\text { Back }_{j}=\sum_{i=1}^{n} b_{i j} ; \text { Forw }_{i}=\sum_{j=1}^{n} b_{i j}
$$

In the traditional input-output model, the two indicators in formula (3) reflect the forward and backward linkage degree between industries respectively, but they are given new meanings in the global input-output model. The former reflects the degree of the backward spatial linkage between a country's economy and the world, and its economic meaning is the sum of the world's output driven by unit final production of country i, reflecting the country's influence in the international economic system. The latter represents the degree of forward spatial linkage of a country's economy with other countries in the world. The economic meaning of forward spatial linkage is the value of country i's production if all countries increase unit final product at the same time, it reflects the country's economic sensitivity to the world.

Although the above two indicators describe the international spatial linkage structures from the perspective of production, the deficiency lies in the lack of connection with the value-added created in the process of cooperation between countries. Further, supposing that $A_{v}$ is an value-added coefficient matrix, and its diagonal element $\mathrm{a}_{\mathrm{vi}}=\mathrm{v}_{\mathrm{i}} / \mathrm{y}_{\mathrm{i}}$ represents the value-added corresponding to the unit output of country $i$. According to the input-output theory, the value-added expression can be obtained as follows:

$$
\mathrm{Val}=\mathrm{A}_{\mathrm{v}} \mathrm{BF}
$$

Based on formula (4), the value-added of country i can be expressed as:

$$
V a l_{i}=\sum_{j=1}^{n} v_{i} b_{i, j} f_{j}
$$

Equation (5) shows that under the global input-output analysis framework, countries in the world form a production network through intermediate goods trade and interrelate with each other, the value-added of a country depends not only on the production of domestic final products but also on the pull of overseas final production. The economic dependency index is used here to indicate the degree of economic dependence of country $i$ on country $j$, which can be expressed as:

$$
\operatorname{Ind}_{i j}=\frac{v_{i} b_{i, j} f_{j}}{\operatorname{Val}_{i}}
$$

This coefficient represents the proportion of the total value-added of country $i$ that is induced by the final production of country $j$. The larger the value of this ratio is, the degree of dependence of country $i$ on country $j$ is greater. When $\mathrm{j}=\mathrm{i}$ in formula (6), the coefficient reflects the degree of dependence of a country's economy on itself. The larger the value of this indicator is, the lower the external dependence of a country's economy is, otherwise is higher.

\subsection{Decomposition of China's Economic Growth Source from the Perspective of Global Linkage}

As pointed out above, under the framework of the global input-output model, as countries form a global production network through trade in intermediate products, economic growth of a country is not only related to internal factors such as its own production technology and final demands, but also depends on the global input-output structure and the production of other countries' final product. Therefore, in the growth accounting of China's economy, the impact of external factors must be considered.

Assuming two different periods $t$ and $t+1$ which represented by the superscript, the difference of the value-added during the two periods can be expressed as:

$$
\begin{gathered}
\Delta \text { Val }=V^{t+1} B^{t+1} F^{t+1}-V^{t} B^{t} F^{t}=0.5 \times\left\{\Delta V\left(B^{t+1} F^{t+1}+B^{t} F^{t}\right)+\left(V^{t+1} \Delta\right.\right. \\
\left.\left.B F^{t}+V^{t} \Delta B F^{t+1}\right)+\left(V^{t} B^{t}+V^{t+1} B^{t+1}\right) \Delta F\right\}
\end{gathered}
$$

The above formula decomposes the value-added of all countries into three parts, that is, the change effect of value-added rate, the change effect of global input-output structure and the change effect of final product output. But in the framework of this analysis, the latter two items can be further decomposed.

Using a research method similar to Miller and Blair (2009), the Leontief inverse matrix can be further decomposed into $\mathrm{B}=\mathrm{M}+\mathrm{N}+\mathrm{T}$, where:

$$
\begin{gathered}
M=\left(\begin{array}{c}
\left(I-A_{11}\right)^{-1}, \cdots, 0 \\
\cdots,\left(I-A_{i i}\right)^{-1}, 0 \\
0, \cdots,\left(I-A_{n n}\right)^{-1}
\end{array}\right) ; \quad N=\left(\begin{array}{l}
B_{11}-\left(I-A_{11}\right)^{-1}, \cdots, 0 \\
\cdots, B_{i i}-\left(I-A_{i i}\right)^{-1}, 0 \\
0, \cdots, B_{n n}-\left(I-A_{n n}\right)^{-1}
\end{array}\right) \\
T=\left(\begin{array}{l}
0, \cdots, B_{1, n} \\
\cdots, 0, B_{i, n} \\
B_{n, 1}, \cdots, 0
\end{array}\right)
\end{gathered}
$$

In formula (8), $\mathrm{M}$ is the domestic multiplier coefficient matrix, and its diagonal element $\left(\mathrm{I}-\mathrm{A}_{\mathrm{ii}}\right)^{-1}$ represents the domestic multiplier effect produced by $\mathrm{i}$ country using domestic intermediate products. $\mathrm{N}$ is a feedback coefficient matrix, and its diagonal element $\mathrm{B}_{\mathrm{ii}}-\left(\mathrm{I}-\mathrm{A}_{\mathrm{ii}}\right)^{-1}$ indicates the 
feedback effect that country i has brought on itself by importing intermediate products from overseas. $\mathrm{T}$ is an overflow coefficient matrix, where the element $B_{i j}(i \neq j)$ represents the external spillover effect of country $i$ exporting intermediate products to foreign countries.

According to formula (8), the change of input-output structure can be further decomposed into three parts related to the domestic multiplier matrix, the feedback matrix, and the overflow matrix, that is, $\Delta \mathrm{B}=\Delta \mathrm{M}+\Delta \mathrm{N}+\Delta \mathrm{T}$. Correspondingly, the final product output can be further decomposed into two parts, namely, domestic and overseas, $\Delta \mathrm{F}=\Delta \mathrm{F}^{\mathrm{d}}+\Delta \mathrm{F}^{\mathrm{s}}$, and the change of added value can be decomposed into:

$$
\begin{gathered}
\Delta \text { Val }=0.5 \times\left\{\Delta \mathrm{V}\left(\mathrm{B}^{\mathrm{t}+1} \mathrm{~F}^{\mathrm{t}+1}+\mathrm{B}^{\mathrm{t}} \mathrm{F}^{\mathrm{t}}\right)+\left(\mathrm{V}^{\mathrm{t}+1} \Delta \mathrm{MF}^{\mathrm{t}}+\mathrm{V}^{\mathrm{t}} \Delta \mathrm{MF}^{\mathrm{t}+1}\right)+\left(\mathrm{V}^{\mathrm{t}+1} \Delta \mathrm{NF}^{\mathrm{t}}+\right.\right. \\
\left.\left.\mathrm{V}^{\mathrm{t}} \Delta \mathrm{NF}^{\mathrm{t}+1}\right)+\left(\mathrm{V}^{\mathrm{t}+1} \Delta \mathrm{TF}^{\mathrm{t}}+\mathrm{V}^{\mathrm{t}} \Delta \mathrm{TF}^{\mathrm{t}+1}\right)+\left(\mathrm{V}^{\mathrm{t}} \mathrm{B}^{\mathrm{t}}+\mathrm{V}^{\mathrm{t}+1} \mathrm{~B}^{\mathrm{t}+1}\right) \Delta \mathrm{F}^{\mathrm{d}}+\left(\mathrm{V}^{\mathrm{t}} \mathrm{B}^{\mathrm{t}}+\mathrm{V}^{\mathrm{t}+1} \mathrm{~B}^{\mathrm{t}+1}\right) \Delta \mathrm{F}^{\mathrm{s}}\right\}
\end{gathered}
$$

Through the above formula, it can be found that under the current international division of labor system, the economic growth of a country depends not only on its own factors (the change effect of value-added rate, the change effect of domestic multiplier and the change effect of domestic final product), but also on the external factors (the feedback effect generated by importing intermediate products, the spillover effect generated by exporting intermediate products and the change effect of overseas final products). Therefore, compared with the traditional growth accounting framework, this paper explores the source of economic growth from a more macroscopic perspective.

\subsection{Data Source and Processing}

This paper adopts the world input-output database (WIOD) funded by the European Commission for analysis. In 2013 and 2016, the database released the input-output table data including the EU countries and major countries (regions) in other parts of the world from 1995 to 2014. In the accounting process of this paper, two aspects of data processing are mainly considered here, that is, the impact of price and exchange rate fluctuations on China's economic growth. For the former, the Double Deflation method is mostly adopted, but the disadvantage of this method is that the added value is only treated as a balance term, resulting in the fact that the result can not reflect the fact of economic growth. Fortunately, WIOD provided 14 comparable input-output tables expressed in the previous year's prices from 1996 to 2009. Therefore, we use the following steps to deal with:

(1) SDA analysis is carried out by using the current price table of period $t$ and the comparable price table of period $t+1$, thus the comparable data of 14 groups based on different years are obtained from 1995 to 2009 , and the remaining data from 2009 to 2014 can be approximated by the same year price table, then 19 sets of data are obtained; (2) Using the annual average exchange rate provided by the China Statistical Yearbook, the 19 sets of data obtained are converted to the value of RMB under the current exchange rate level; (3) For the comparable data based on different years from 1995 to 2009, comparisons can be made based on the data of current price table and comparable price for each period of WIOD. For the two sets of data between 2009 and 2014, the current year price and comparable GDP data provided by the "China Statistical Yearbook" are used for comparison. After obtaining the series of value-added price indexes over the years, it is further converted into the 1995 price index, and the data of (2) is deflated. Finally, the value-added data after the removal of price and exchange rate effects are obtained.

\section{China's Economic External Linkage Between 1995 and 2014}

In the above model, multiple indicators are defined to describe the degree of spatial connection of the global economy from different perspectives. Figure 1 first gives the trends of the overall world-wide and China's forward (backward) economic linkages between 1995 and 2014. It is found that the overall linkage of the world economy increased from 1.99 in 1995 to 2.18 in 2014 , indicating that the establishment of the international division of labor system made a certain degree of improvement of economic linkage in the world. For China, there was no obvious difference between the forward and backward linkage degrees in 1995, 2.33 and 2.30 respectively, slightly higher than the world's average level at that time. However, the index of China's economic forward linkage reached 4.55 in 2014, an increase of 2.22 compared to 1995. By comparison, the degree of backward linkage in 2014 was only 2.64 , increasing by only 0.34 during the period 1995-2014. The above analysis shows two points: First, with the establishment of the international division of labor system, China's economy was successfully integrated into the global value chain during this period; Second, the influence induced by the external world on China's economy was deepening, while the influence of China on other countries was not obvious.

Figure 2 further shows the trends of spatial distribution of China's forward linkage between 1995 and $2014^{1}$. From the table, it can be seen that during the analysis period, the degree of forward linkage between China and the external countries rose from 0.25 in 1995 to 2.14 in 2014, which means that China's sensitivity to external economies raised dramatically. Among them, the degree of forward linkage with European countries rose from 0.13 at the beginning of the period to 1.3 at the end of the period, increasing by 1.16 during the analysis period, which is the most significant among all regions. The forward linkage between China's economy and North America rose from 0.02 in 1995 to the highest point of 0.16 in 2011 , but then slowly declined to 0.13 in 2014 , indicating that

1 Here, we classify countries in the world input-output table of which Europe includes countries of the European Union, North America includes the United States, Canada and Mexico, and Asia includes Japan, South Korea, Indonesia, India and Taiwan, and the remaining countries are marked as "other". 
the sensitivity of China's economy to North America showed a trend of "first increasing and then decreasing". In contrast to North America, the sensitivity of China's economy to neighboring Asian countries rose from 0.07 in 1995 to 0.47 in 2011, and fell sharply to 0.35 in 2012 , but soon reached the highest point of 0.49 in 2014. For "other" regions including a large number of developing countries, China's economic sensitivity increased from 0.02 in 1995 to 0.16 in 2011, but then rose significantly to 0.22 in 2014 , indicating that under the background of the prevalence of global trade protectionism, China's economy increased its sensitivity to neighboring countries and developing countries.

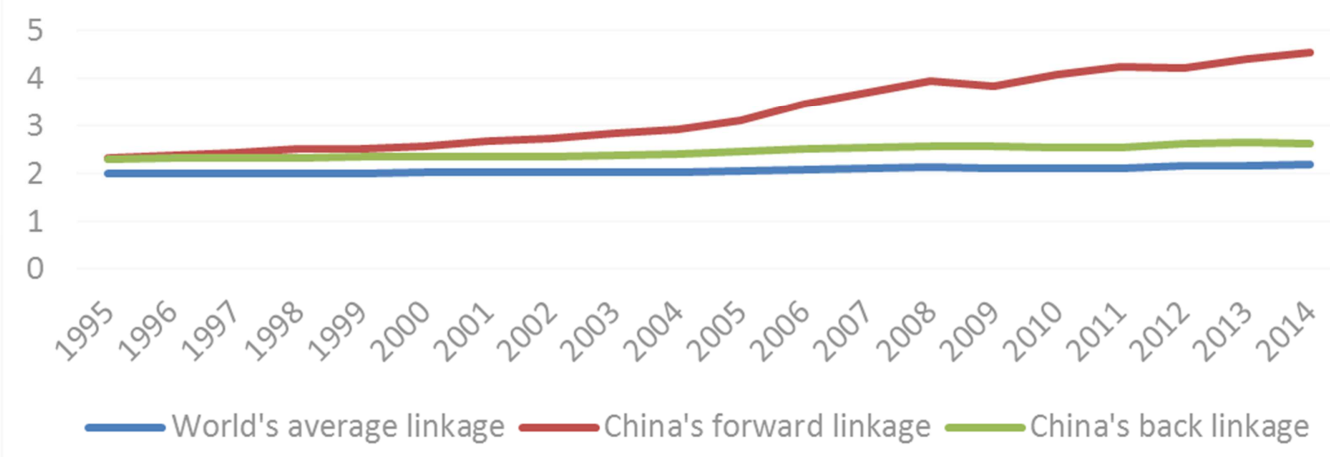

Figure 1. Change Trends of World's average linkage and China's Forward (Backward) linkage during 1995-2014.

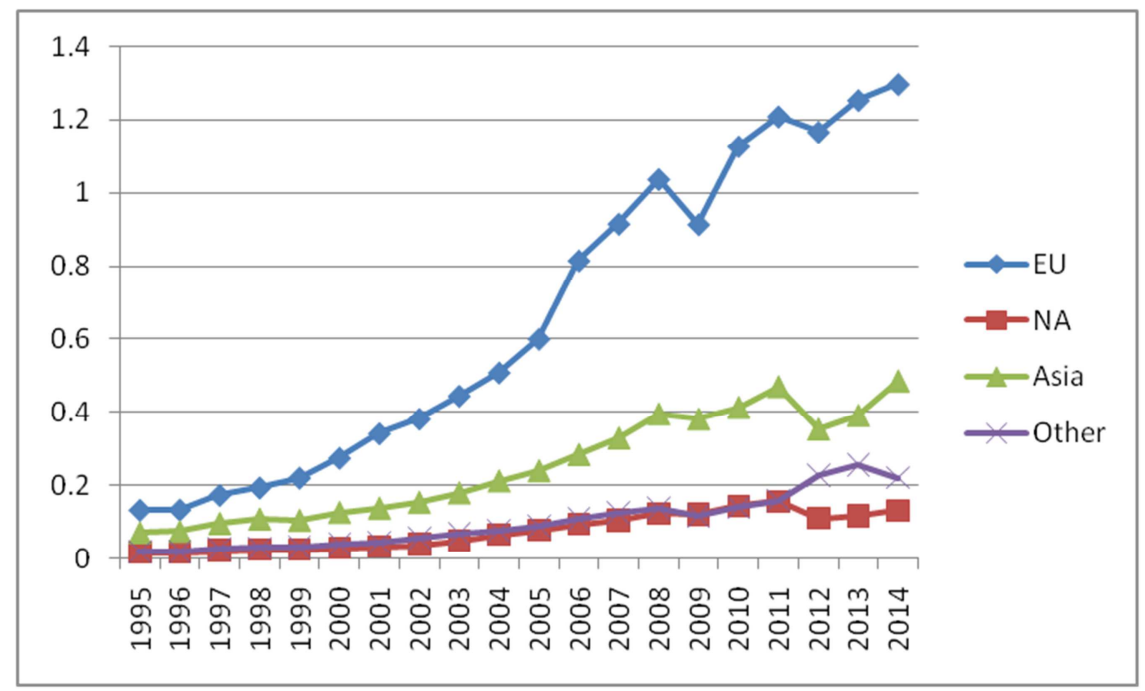

Figure 2. Spatial Distribution of China's Forward Linkages between 1995 and 2014.

Table 2 further gives the distribution of forward linkage degree of China's three sectors from 1995 to 2014. For the agricultural sector, its forward linkage degree rose slightly from 1.52 in 1995 to 1.65 in 2014 which was not significant during the analysis period. On contrast to this, the value of industrial sector's forward linkage increased from 3.48 in 1995 to 8.78 in 2011, of which the forward linkage with the EU and Asian economies increased from 0.26 and 0.12 in 1995 to 2.94 and 1.02 in 2014 respectively. The degree of forward linkage of the service sector increased from 1.98 in 1995 to 3.24 in
2014. Among them, the output value of other countries increased by the unit final production rose from 0.18 at the beginning of the period to 1.22 at the end of the period, showing a significant increase. The above analysis shows that during the analysis period, China's economic sensitivity to the external world had been improved. The regional level is mainly embodied in countries such as Europe and Asia, and the sector level is concentrated in the industrial and service sectors.

Table 2. Spatial Distribution of China's Forward Linkages during 1995-2014.

\begin{tabular}{|c|c|c|c|c|c|c|c|}
\hline & & Europe & North America & Asia & Others & Self & Total \\
\hline \multirow{2}{*}{ Agriculture } & 1995 & 0.04 & 0.01 & 0.02 & 0.01 & 1.45 & 1.52 \\
\hline & 2014 & 0.17 & 0.02 & 0.06 & 0.04 & 1.36 & 1.65 \\
\hline \multirow{2}{*}{ Industry } & 1995 & 0.26 & 0.04 & 0.12 & 0.07 & 3.00 & 3.48 \\
\hline & 2014 & 2.94 & 0.32 & 1.02 & 0.64 & 3.86 & 8.78 \\
\hline \multirow{2}{*}{ Service } & 1995 & 0.11 & 0.01 & 0.04 & 0.02 & 1.80 & 1.98 \\
\hline & 2014 & 0.78 & 0.06 & 0.20 & 0.17 & 2.02 & 3.24 \\
\hline
\end{tabular}


Figure 3 presents the change trends of spatial distribution of the backward linkages of China's economy from 1995 to 2014. From the figure, it can be found that the output of other countries induced by unit final products in China had increased from 0.22 in 1995 to the highest point of 0.34 in 2005 , and then gradually dropped back to 0.22 in 2014, indicating that the influence of China's economy on the external world had gone through the trend of inverted $U$, and had not been effectively promoted during the analysis period. In terms of sub-regions, the influence coefficient of China's economy on Europe, North America, Asia and other countries in 1995 was $0.04,0.03,0.15$ and 0.05 respectively, indicating that China had the highest influence on Asia at the beginning of the analysis period, followed by other regions, and had low impact on Europe and North America. In 2014, the influence coefficient of China's economy on Europe, North America, Asia, and other countries changed to $0.03,0.02,0.06$, and 0.12 , respectively, showing that at the end of the period, the influence of China's economy on Europe, North America, and Asia did not rise but decreased. On the contrary, China significantly increased its economic influence on other regions including a large number of "developing countries."

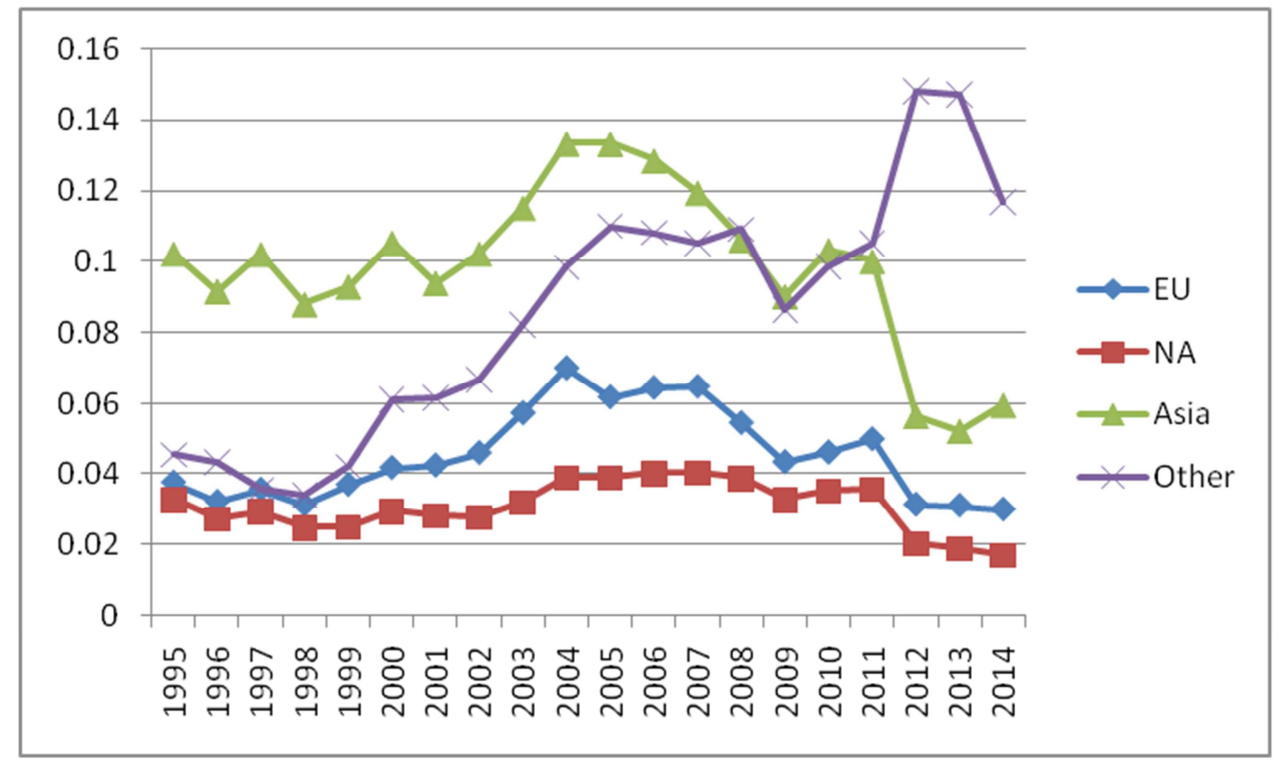

Figure 3. Distribution of China's Economic Backward Linkages during 1995-2014.

In terms of sectors, the degree of backward linkage of China's agricultural sector and service sector rose from 1.89 and 2.18 in 1995 to 2.18 and 2.27 in 2014 respectively, which were not significant during the period of analysis. In sharp contrast to this, the backward linkage of industrial Sector increased from 2.83 in 1995 to 3.46 in 2014, an increase of 0.63 during the period of analysis, which is significant in the three industries. After in-depth observation of Table 3, it is found that the internal and external output induced by each unit China's industrial final output increased from 2.5 and 0.33 in 1995 to 3.09 and 0.37 in 2014, indicating that its influence on the external upstream economies was extremely limited and had not been effectively improved during the analysis period. From the view of the region, the influence of China's service sector on Europe, North America, and Asian countries had shown a certain downward trend, but its influence on "other" regions had increased.

Table 3. Distribution of China's Economic Backward Linkages during 1995-2014.

\begin{tabular}{|c|c|c|c|c|c|c|c|}
\hline & & Europe & North America & Asia & Others & Self & Total \\
\hline \multirow{2}{*}{ Agricultural Sector } & 1995 & 0.02 & 0.02 & 0.05 & 0.03 & 1.76 & 1.89 \\
\hline & 2014 & 0.02 & 0.01 & 0.03 & 0.08 & 2.04 & 2.18 \\
\hline \multirow{2}{*}{ Industrial Sector } & 1995 & 0.05 & 0.05 & 0.15 & 0.08 & 2.50 & 2.83 \\
\hline & 2014 & 0.05 & 0.02 & 0.08 & 0.22 & 3.09 & 3.46 \\
\hline \multirow{2}{*}{ Service Sector } & 1995 & 0.04 & 0.03 & 0.08 & 0.05 & 1.99 & 2.18 \\
\hline & 2014 & 0.02 & 0.01 & 0.03 & 0.08 & 2.12 & 2.27 \\
\hline
\end{tabular}

The above analysis is mainly based on the Leontief inverse matrix, and does not consider the impact of the initial inputs and the final products. Figure 4 shows the change trends of China's economy as a whole and various sectors' self-dependence during the period of 1995-2014. From Figure 4 , it is showed that China's economic self dependence decreased from $91.04 \%$ in 1995 to the lowest point of $84.26 \%$ in 2006 , but rose to $90.36 \%$ in 2014 , which presented the $\mathrm{U}$ tendency of "increasing firstly and then decreasing" during the analysis period. Among them, the self dependence of the industrial sector was always the lowest in the three sectors, from $89.46 \%$ in 1995 to $81.59 \%$ in 2006 , and then increased to $88.44 \%$ in 2014 . In contrast to the industrial sector, the self dependence of the agricultural sector was the highest in the 
three industries, dropping from $93.56 \%$ in 1995 to $87.93 \%$ in 2007 , and then increased to $91.9 \%$ in 2014 , decreasing by about 1.66 percentage points during the analysis period. The degree of self dependence of the service sector fell from $91.79 \%$ in 1995 to $84.26 \%$ at the lowest point in 2006 and then increased to $91.88 \%$ at the end of the period. During the period of analysis, it did not fall but increased slightly instead. The above analysis shows that although China's economic self dependence had declined in the early stage of analysis, it could be seen an obvious upward trend after 2006.

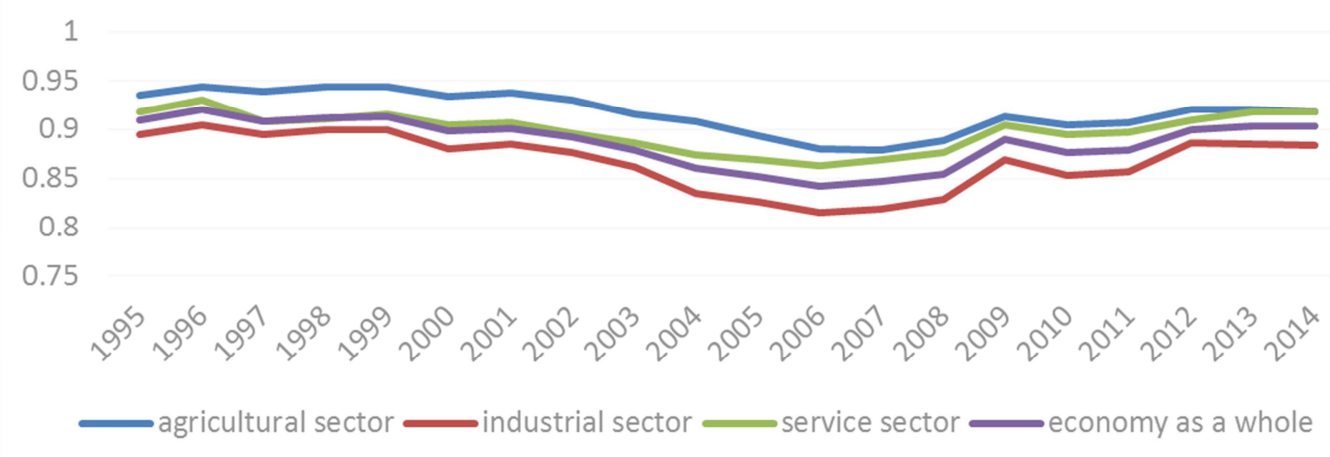

Figure 4. Change Trends of Self Dependence of China's Economy from 1995 to 2014.

Figure 5 further gives the spatial distribution of China's value-added (initial input) dependence on foreign economy during the analysis period. It is found that the external dependence of China's economy rose from $8.96 \%$ in 1995 to $15.74 \%$ in 2006 , but then dropped to $9.64 \%$ in 2014 , with an increase of about 0.68 percentage points during the analysis period. Among them, the dependence of China's economy on North America, Europe, and Asian countries showed a similar trend of "first rising and then decreasing", and the decline rate exceeded the increase rate, which indicating the dependence of China's economy on these areas showed a downward trend during the period from 1995 to 2014. In contrast, the dependence of China's economy on "other" regions rose from $2.2 \%$ in 1995 to the highest point of $4.58 \%$ in 2006. Although it was affected by the financial crisis and fell to $3.07 \%$ in 2009 , it quickly rebounded to $4.42 \%$ in 2014 , increasing by about $2.22 \%$ during the period of $1995-2014$, which is the only region where China's economic dependence on foreign countries had increased. The above analysis indicated that China had reduced its economic dependence on developed countries such as Europe and the United States after the financial crisis in 2008, and increased its dependence on developing countries at the same time.

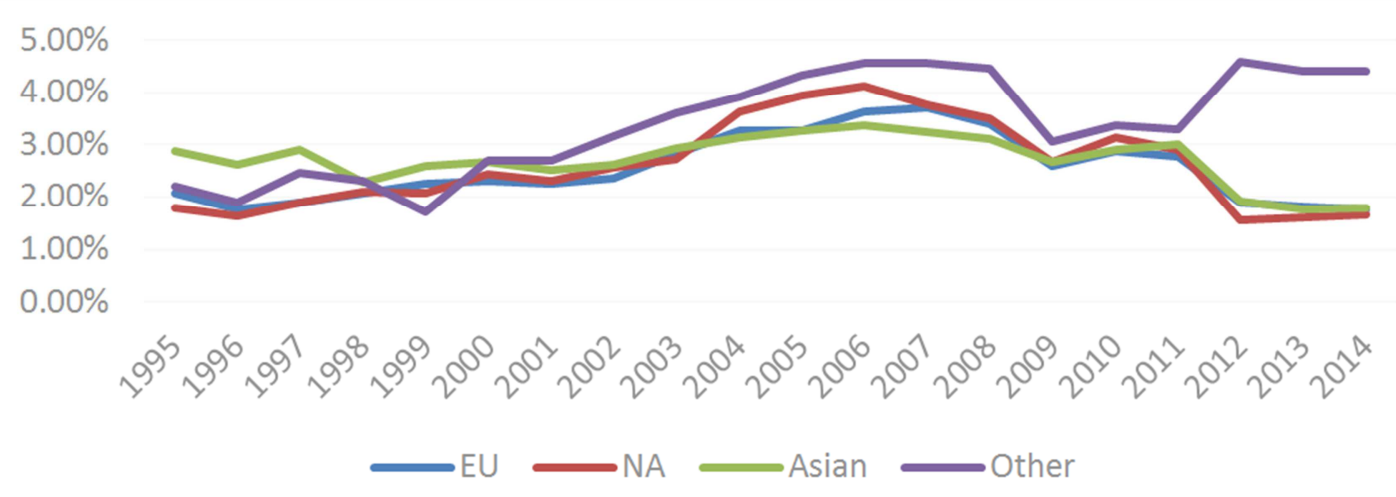

Figure 5. Distribution of China's Economic External Dependence during 1995-2014.

There are differences of the dependence between the regions in the world and different sectors. For example, the degree of external dependence of agricultural sector rose from $6.44 \%$ in 1995 to $9.31 \%$ in 2014 , which rose by 2.87 percentage points during the period of analysis, mainly concentrated in "other" regional countries, that is, a large number of developing countries. The degree of external dependence of industrial sector was the highest in the three sectors, rising from $10.5 \%$ in 1995 to $11.56 \%$ in 2014 during the analysis period, of which the dependence on North America, Europe and Asia declined, but the degree of dependence on the "other" regions rose from $2.71 \%$ in 1995 to $4.8 \%$ in 2014 . The degree of external dependence of service sector was the lowest in the three sectors, and fell from $8.21 \%$ in 1995 to $8.21 \%$ in 2014, of which the dependence on North America, Europe and Asia declined while the degree of dependence on the "other" regions increased from $1.55 \%$ at the beginning of the period to $4.28 \%$ at the end of the period. 
Table 4. Distribution of External Dependence of China's Three sectors'during 1995-2014 (\%).

\begin{tabular}{|c|c|c|c|c|c|c|}
\hline & & Europe & North America & Asia & Others & Total \\
\hline \multirow{2}{*}{ Agricultural Sector } & 1995 & 1.37 & 1.29 & 2.23 & 1.55 & 6.44 \\
\hline & 2014 & 1.48 & 1.53 & 1.69 & 3.4 & 9.31 \\
\hline \multirow{2}{*}{ Industrial Sector } & 1995 & 2.15 & 2.30 & 3.38 & 2.71 & 10.5 \\
\hline & 2014 & 2.09 & 2.25 & 2.41 & 4.8 & 11.56 \\
\hline \multirow{2}{*}{ Service Sector } & 1995 & 2.43 & 1.34 & 2.56 & 1.88 & 8.21 \\
\hline & 2014 & 1.51 & 1.13 & 1.21 & 4.28 & 8.12 \\
\hline
\end{tabular}

Figure 6 further presents the spatial distribution of China's economic openness based on final products during 1995-2014. It is found that the degree of China's economic openness rose from $11.47 \%$ in 1995 to a maximum point of $18.25 \%$ in 2005 , but then dropped to $10.89 \%$ in 2014 , decreasing by about 0.58 percentage points during the analysis period. Similar to the dependence index, the degree of China's economic openness on North America, Europe and Asia presented a trend of "increasing firstly and then decreasing", and the decline rate exceeded the increase rate, indicating that the openness degree of China's economy to these areas had declined during the analysis period. In contrast, the openness of China's economy to "other" areas rose from $2.5 \%$ in 1995 to a maximum of $6.24 \%$ in 2008 . Although it was affected by the financial crisis, it quickly rebounded to $6.04 \%$ in 2014 , increasing by about $3.54 \%$ during 1995-2014, indicating that in the process of globalization, whether it is the degree of external dependence or the degree of openness, China's economy had strengthened its links with "other" regions, including a large number of developing countries.

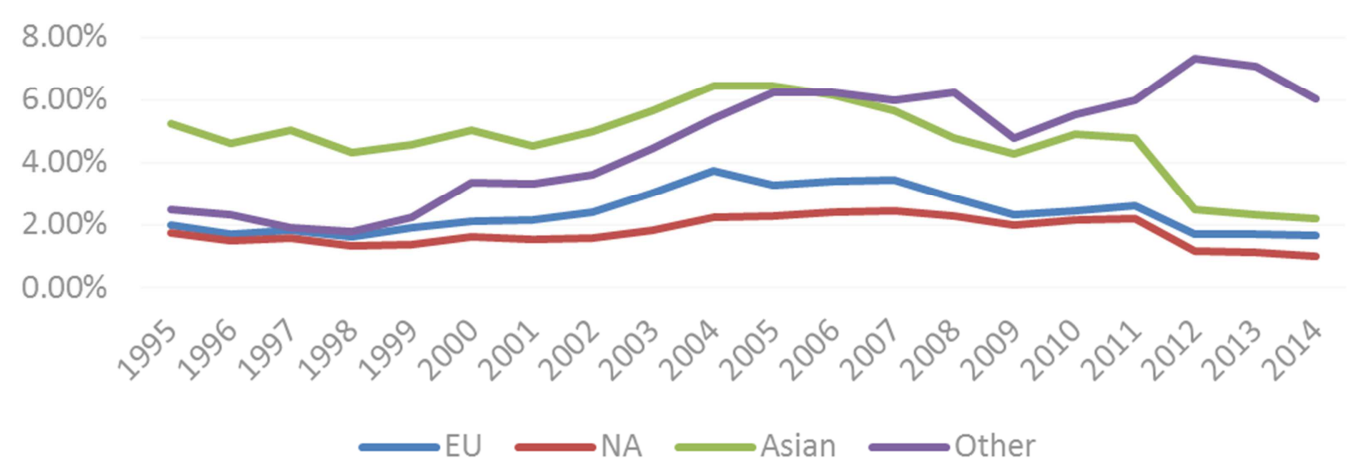

Figure 6. Change Trends of China's Final Products'Spatial Distribution between 1995 and 2014.

Table 5 further gives the spatial distribution of China's three sectors' openness from the perspective of final products during the analysis period. From the table, it can be found that the opening degree of the agricultural sector was the lowest among the three sectors, decreasing from $5.83 \%$ in 1995 to $5.71 \%$ in 2014 , and the main opening areas had been transferred from the Asian region to the "other" areas during the period. The degree of the industrial sector was the highest among the three sectors and rose from $14.18 \%$ to $14.23 \%$ during the analysis period. Among them, the degree of openness in the Asian region decreased from $6.62 \%$ in 1995 to $2.89 \%$ in 2014 , showing the most significant decline in all regions, and the openness of the "other" regions rose from $3.08 \%$ at the beginning of the period to $8.03 \%$ at the end of the period. The service sector's openness decreased from $8.57 \%$ to $6.06 \%$ during the period of analysis, dropping by approximately 1.5 percentage points. Among them, the degree of openness to North America, Europe, and Asian countries decreased while the degree of openness to "other" regional countries rose from $1.83 \%$ in 1995 to $3.15 \%$ in 2014 . The above analysis shows that while the three industries of China reduced their openness to Europe, North America and major Asian countries, they greatly improved their openness to developing countries.

Table 5. Spatial Distribution of China's Three Sectors' Openness between 1995 and 2014 (\%)

\begin{tabular}{|c|c|c|c|c|c|c|}
\hline & & Europe & North America & Asia & Others & Total \\
\hline \multirow{2}{*}{ Agricultural Sector } & 1995 & 1.04 & 1.08 & 2.34 & 1.36 & 5.83 \\
\hline & 2014 & 0.78 & 0.65 & 1.13 & 3.14 & 5.71 \\
\hline \multirow{2}{*}{ Industrial Sector } & 1995 & 2.38 & 2.09 & 6.62 & 3.08 & 14.18 \\
\hline & 2014 & 2.08 & 1.24 & 2.89 & 8.03 & 14.23 \\
\hline \multirow{2}{*}{ Service Sector } & 1995 & 1.63 & 1.38 & 3.73 & 1.83 & 8.57 \\
\hline & 2014 & 1.06 & 0.66 & 1.18 & 3.15 & 6.06 \\
\hline
\end{tabular}




\section{Decomposition of China's Economic Growth from the Perspective of Global Linkage}

In the process of global integration, countries or regions have formed a global production network through intermediate products trade, so a country's economic growth depends not only on its own factors but also on the global input-output structure and changes in output of overseas final products. Therefore, exploring the source of China's economic growth from the perspective of global linkages will enable us to understand its economic development from a more macro perspective, so as to better grasp its future development trend.

Table 6 shows the decomposition result of China's economy growth from 1995 to 2014. For China's economy as a whole, the effect of value-added rate, the domestic multiplier effect and the domestic final product effect are -33338, 20750 and 252580 billion yuan respectively, and the total contribution shares of internal factors was $83.96 \%$. Correspondingly, the feedback effect, the spillover effect and the overseas final product effect are 753, 33733 and 11346 billion yuan respectively, and the total contribution shares of external factors was $16.04 \%$. From the point of sectors level, both the scale and the growth rates of the industrial sector are the highest among the three sectors in China; On the contrary, both the scale and the growth rates of agriculture sector was the lowest among three industries; The service sector was between the two. After depth observation, it can be found that the contribution of internal factors to the growth of the three sectors are $85.26 \%, 80.06 \%$ and $89.61 \%$ respectively. Correspondingly, the contribution of external factors to the three industries are $14.74 \%, 19.94 \%$ and $10.39 \%$, indicating that in the process of global economic integration, the sources of economic growth of different sectors in China were also different, the external factors played an more important role in the growth of industrial economy, and the growth of service sector was more dependent on the internal factors.

Table 6. Decomposition of China's Economics Growth between 1995 and 2014 Unit: RMB 100 million in 1995 price.

\begin{tabular}{|c|c|c|c|c|c|c|c|c|}
\hline & $\begin{array}{l}\text { Average } \\
\text { Growth Rate }\end{array}$ & $\begin{array}{l}\text { Value-Added } \\
\text { rate effect }\end{array}$ & $\begin{array}{l}\text { Domestic } \\
\text { Multiplier Effect }\end{array}$ & $\begin{array}{l}\text { Feedback } \\
\text { Effect }\end{array}$ & $\begin{array}{l}\text { Spillover } \\
\text { Effect }\end{array}$ & $\begin{array}{l}\text { Domestic Final } \\
\text { Product Effect }\end{array}$ & $\begin{array}{l}\text { Foreign Final } \\
\text { Product Effect }\end{array}$ & Total \\
\hline Agricultural & $4.00 \%$ & -636 & -3824 & 32 & 1333 & 15930 & 619 & 13454 \\
\hline Industrial & $10.51 \%$ & -34033 & 19242 & 562 & 24236 & 145176 & 7671 & 162854 \\
\hline Service & $10.34 \%$ & 1331 & 5331 & 159 & 8164 & 91474 & 3057 & 109516 \\
\hline Total & $9.59 \%$ & -33338 & 20750 & 753 & 33733 & 252580 & 11346 & 285824 \\
\hline
\end{tabular}

Table 7 further gives the decomposition result of China's economic growth in different periods between 1995 and 2014. From the table, it can be seen that before China's accession to the WTO, the average annual growth rate of China's economy was about $8.53 \%$ during the period from 1995 to 2002 . The total contribution of internal factors such as the effect of value-added rate, the domestic multiplier effect, and the domestic final product effect was $84.24 \%$, correspondingly, the feedback effect, the spillover effect, and the overseas final product effect contributed $15.76 \%$. After China's accession to the WTO, China's economic growth rate increased to $11.52 \%$ between 2002 and 2008. The contribution of internal factors decreased to $74.35 \%$ while the contribution of external factors increased to $25.65 \%$. The outbreak of the financial crisis in 2008 had an important impact on China's economy. During this period, China's economy mainly achieved its goal of high speed growth by stimulating domestic demand. The contribution of internal factors to China's economy increased to $94.8 \%$, while the contribution rate of external factors dropped to $5.2 \%$. Since 2011 , China's economic growth has slowed down, and the average annual growth rate dropped to $8.14 \%$ from 2011 to 2014 , which is the lowest in the analysis period. The contribution shares of internal and external factors to China's economy growth between 2011 and 2014 were $87.04 \%$ and $12.96 \%$ respectively.

Table 7. Decomposition of China's Economic Growth at Different Stages from 1995 to 2014 Unit: RMB 100 million in 1995 price.

\begin{tabular}{|c|c|c|c|c|c|c|c|c|}
\hline & $\begin{array}{l}\text { Average } \\
\text { Growth Rate }\end{array}$ & $\begin{array}{l}\text { Value-Added } \\
\text { rate effect }\end{array}$ & $\begin{array}{l}\text { Domestic } \\
\text { Multiplier Effect }\end{array}$ & $\begin{array}{l}\text { Feedback } \\
\text { Effect }\end{array}$ & $\begin{array}{l}\text { Spillover } \\
\text { Effect }\end{array}$ & $\begin{array}{l}\text { Domestic Final } \\
\text { Product Effect }\end{array}$ & $\begin{array}{l}\text { Foreign Final } \\
\text { Product Effect }\end{array}$ & Total \\
\hline $1995-2002$ & $8.53 \%$ & -2381 & -2285 & 131 & 6062 & 44290 & 1221 & 47039 \\
\hline $2002-2008$ & $11.52 \%$ & -23445 & 11383 & 649 & 20565 & 86139 & 4340 & 99631 \\
\hline $2008-2011$ & $9.73 \%$ & -539 & 2696 & -34 & 1485 & 61032 & 2013 & 66652 \\
\hline 2011-2014 & $8.14 \%$ & -6972 & 8956 & 6 & 5622 & 61119 & 3772 & 72502 \\
\hline
\end{tabular}

From table 7, it can be found that the value-added rate effect of China's economy had always been negative during the analysis period, which was obviously related to the increase in the proportion of the intermediate input in the process of industrialization. Figure 7 a shows the change trends of input coefficients of China's overall economy and various sectors during the period 1995-2014. It can be seen from the figure that the overall intermediate input coefficient of China's economy increased from 0.61 in 1995 to 0.67 in 2014. In the view of the sectors, the value of intermediate input coefficient of the agricultural sector was the lowest and the growth rate was very small, which is not significant to the effect of China's economic value-added rate. On the contrary, the intermediate input coefficient of the industrial sector was not only the highest in the three sectors, but also the most significant increase in the analysis phase, rising from 0.71 in 1995 to 0.78 
in 2014, which is the main cause of the negative effect of China's economic value-added rate. Unlike the agricultural and industrial sectors, the intermediate input coefficient of the service sector did not rise in the period of analysis, on the contrary, it fell from 0.48 in 1995 to 0.46 in 2014 . It can be expected that with the gradual increase in the proportion of the service industry in economy during the post-industrialization stage, the negative impact of the value-added rate on economic growth will gradually diminish or even disappear.

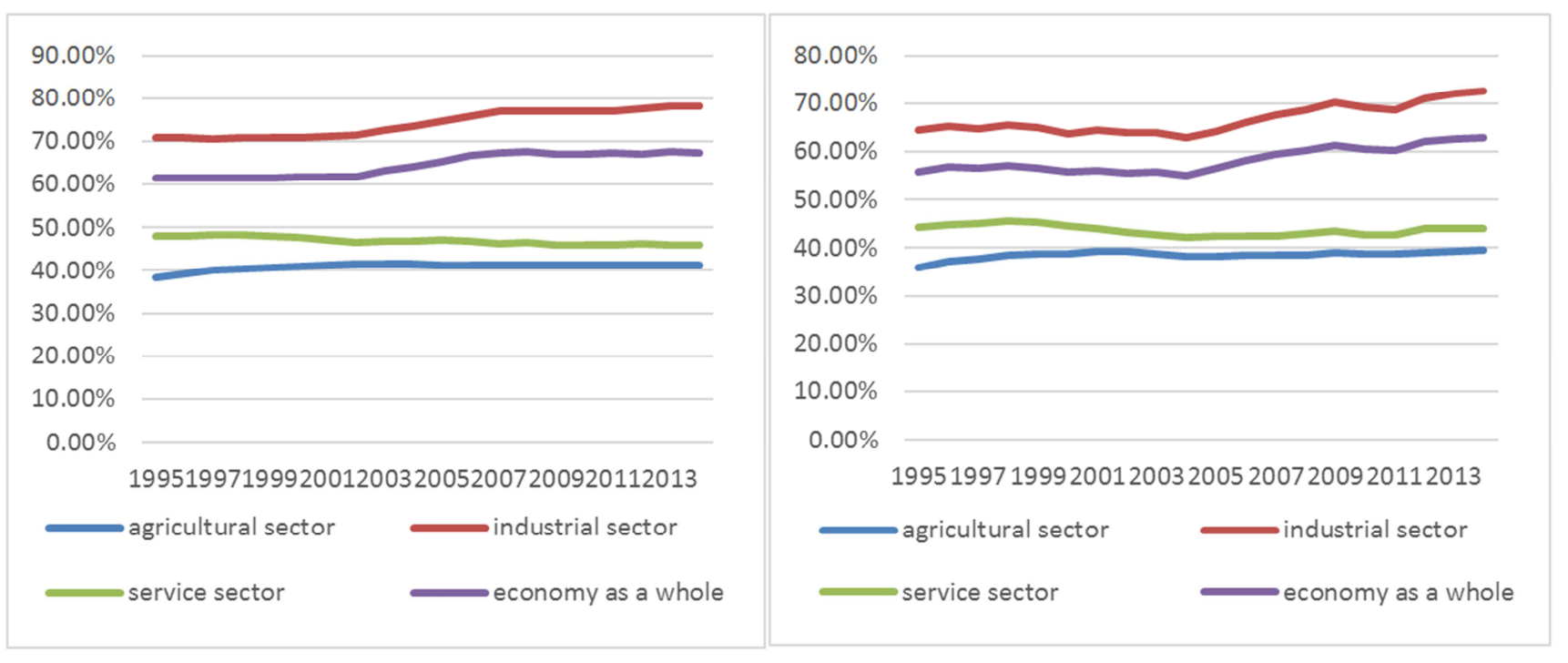

a. Total Intermediate Input Coefficient

b. Local Intermediate Input Coefficient

Figure 7. Change Trends in Intermediate Input Coefficients of China's Economy during the period 1995-2014.

The impact of domestic multiplier effect on China's economic growth is further shown in Table 7 . The data in the table shows that the domestic multiplier effect had a negative impact on China's economy before its entry of WTO at the end of 2002. After joining the World Trade Organization, the domestic multiplier effect changed obviously. The total amount of the multiplier effect was 23034 billion yuan from 2002 to 2014, and the contribution to China's economic growth at this stage was $9.65 \%$. Since the domestic multiplier effect is mainly related to the input ratio of local intermediate products in the production process, Figure $7 \mathrm{~b}$ shows the change trends in the intermediate input coefficients of whole China and various sectors during 1995-2014. From the figure, it can be seen that before entering the WTO, China's local intermediate input coefficient remained fluctuating around 0.56 slightly, but after entering the WTO, the local intermediate input coefficient rapidly increased to 0.63 in 2014. After further observation, it can be found that the increase of local intermediate input coefficient of the agricultural and service sectors is limited. On the contrary, the local intermediate input coefficient of the industrial sector remained near 0.64 before joining the WTO, but increased rapidly to 0.73 in 2014 after the entry of WTO. The above analysis shows that after China's accession to the WTO, more and more industrial products are assembled in China, which leads to the positive impact of the domestic multiplier effect on China's economy.

The feedback effect is mainly related to the use of imported intermediate goods in the process of production. The higher the proportion is, the more obvious the feedback effect is. From Table 6, it can be found that the feedback effect had no obvious impact on China's economy, only 753 billion yuan during 1995-2014, accounting for $0.26 \%$ of the total economic growth. In a phased way, the feedback effect experienced a process of increasing first and then decreasing, and even was negative from 2008 to 2011. In order to find out the reasons for this, Figure 8 shows the change trends of the input coefficients of imported intermediate products in China from 1995 to 2014. It is found that the proportion of the overall imported intermediate products rose from 5.59\% in 1995 to the highest point of $9.01 \%$ in 2004 , and then gradually dropped to $4.33 \%$ in 2014. In terms of sectors, the proportion of imported intermediate products of the industrial sector was the highest, followed by the service sector, and the agricultural sector was the lowest. Among them, the proportion of imported intermediate products of the service sector fell from $4.81 \%$ in 2004 to $1.99 \%$ in 2014 which was the most significant among the three industries. It can be expected that with the rapid development of the service sector, the feedback effect will have little impact on China's economic growth. 


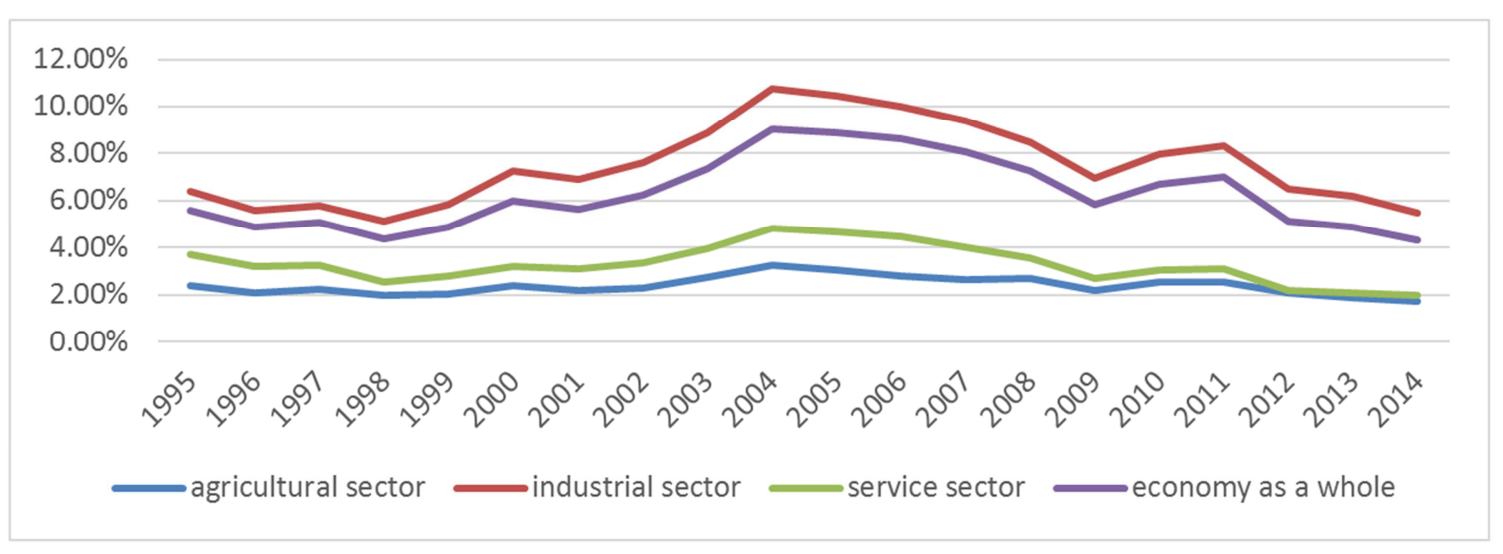

Figure 8. The Input Coefficients of Imported Intermediate products of China during 1995-2014.

From table 6, it is found that the external spillover effect on China's economy from 1995 to 2014 was 3373.3 billion yuan, accounting for $11.8 \%$ of the total economic growth in this stage, which is one of the important factors driving the rapid growth of China's economy. Figure 9 shows the change trends in the spillover effect of each sector in the analysis period. It can be found from the figure that, except for the negative spillover effects caused by the two financial crises in 1998 and 2008, the spillover effect of other countries on China's economy in other years was positive and fell back after reaching its highest value during 2005-2006. Further observation of Figure 6 shows that the spillover effect of the external world on China's economy is mainly reflected in the industrial sector, indicating that the role of the "world factory" in the international division of labor determines that China had a serious dependence on the external market, which is in full agreement with the results obtained in the analysis of the spatial linkage above. The above analysis shows that the spillover effect was closely related to China's accession to the World Trade Organization in 2002 and its positive impact on China's economy will weaken gradually as time goes on.

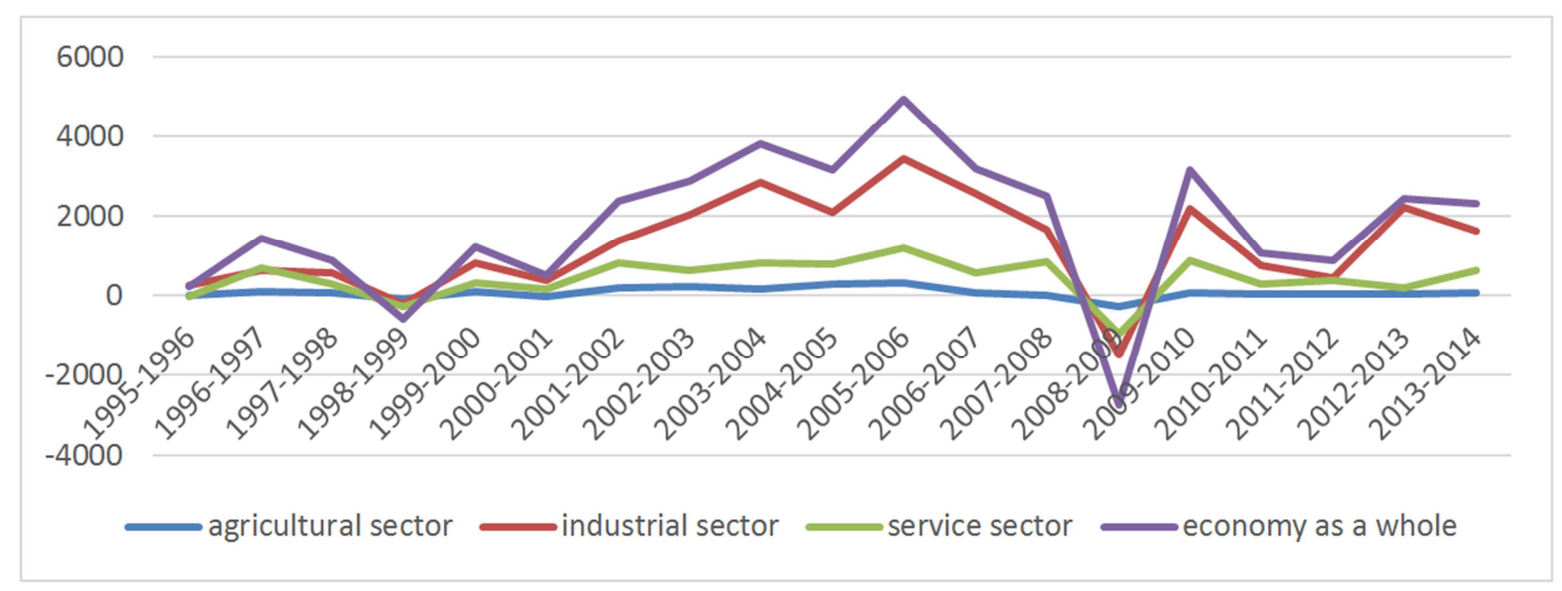

Figure 9. Change Trends in Spillover Effects of China's economy from 1995 to 2014.

Table 6 shows the impact of changes in final product output on China's economic growth. In the period from 1995 to 2014, the final product output effect totaled 26.39 trillion yuan. The part of the final product output effect associated with the change in domestic final product output was 25.26 trillion yuan, while the part related to the change in output of overseas final products was 1.13 trillion yuan, showing that China's rapid economic growth depended more on the pull of domestic rather than overseas final product production. Table 6 further gives the growth rate of the final product output of the three sectors in the period of 1995-2014. From the table, it can be found that there were great differences between different sectors. For example, the average growth rate of the agricultural sector from 1995 to 2014 was $2.34 \%$, which was the lowest among the three sectors. On the contrary, the average annual growth rate of the industrial was $11.45 \%$ in the analysis period, which was the highest among the three sectors. Especially during the period from 2002 to 2007 after China's accession to the WTO, the value of this indicator was once as high as $15.53 \%$, showing a strong developing trend. The output of the final products of the service sector in China also maintained a high growth level, and the average annual growth rate of the analysis period was up to $11.43 \%$. However, different from the industrial sector, the impact of joining the World Trade Organization was not obvious on the production of the service sector, indicating that China's position of the world factory in the international division of labor system promoted the development of China's industrial sector rather than the service sector. 
Table 8. Phased Growth Rate of Final Product in Domestic and Overseas from 1995 to 2014 (\%).

\begin{tabular}{|c|c|c|c|c|c|c|c|c|c|c|}
\hline & \multicolumn{2}{|l|}{$1995-2002$} & \multicolumn{2}{|l|}{ 2002-2007 } & \multicolumn{2}{|l|}{$2007-2011$} & \multicolumn{2}{|l|}{ 2011-2014 } & \multicolumn{2}{|l|}{$1995-2014$} \\
\hline & Domestic & Overseas & Domestic & Overseas & Domestic & Overseas & Domestic & Overseas & Domestic & Overseas \\
\hline Agriculture & 2.69 & 1.52 & -3.91 & 1.56 & 6.91 & 6.62 & 6.36 & 1.42 & 2.34 & 2.57 \\
\hline Industry & 9.13 & 2.00 & 15.53 & 3.35 & 11.57 & 1.64 & 10.08 & 0.61 & 11.45 & 2.05 \\
\hline Service & 10.87 & 3.09 & 11.51 & 2.99 & 9.79 & 2.48 & 12.94 & 1.40 & 11.13 & 2.67 \\
\hline
\end{tabular}

Table 8 shows the phased growth rate of the final product of the three sectors during the analysis period. Compared with the data of domestic and overseas, the differences were reflected in the following aspects: Firstly, there were great differences in the growth rate of the final product of the domestic sectors, on the contrary, the difference of the overseas final product's average growth rate among the three sectors from 1995 to 2014 was not significant; Secondly, for the industry, its final product growth rate was ranked first of the three sectors in China and last in the rest countries in the world, which shows that in the process of economic globalization, the assembly process of industrial production was gradually transferred to China; Finally, the final use structure was different. For the rest countries in the world, the final demand structure was always stable during the analysis period. In contrast, China's economy relied on investment-driven but suppressed consumer demand at the same time, which was an extensive and not sustainable growth mode.

\section{Conclusion}

Using the world input-output table from 1995 to 2014, this paper analyzes the current situation and evolution rules of China's economic external linkages, and accounts China's economic growth from the perspective of global spatial linkage. The conclusions include: 1. During the period of analysis, China's economic forward linkage greatly increased, while the change of the backward linkage was not significant. Considering the added value factors, while China's economy had improved its rate of international division of labor, the degree of external induction also had been greatly improved; 2 . By examining the overseas dependence index, it can be found that China's dependence on the Asian region declined, while the dependence on the North American and developing countries increased during the period of analysis,; 3 . It can be found that along with China's gradual integration into the global product division system, the dynamic mechanism of its economic growth was also changing.

The analysis shows that the rapid growth of China's economy in the past decades is the result of external factors and internal factors. For the external factors, the change of global input-output structure brought positive feedback effect, spillover effect and overseas final product production effect; in terms of internal factors, although the effect of added value rate was negative, the domestic multiplier effect and the domestic final product production effect ensured its sustained and stable growth. However, it can be seen that after entering the middle-income stage, China's economy will face new and severe challenges: Firstly, the positive impact of the changes in the global input-output structure on China's economy is mostly short-term and temporary, and will weaken with the passage of time. Secondly, its structure of the final product using investment will not be sustainable. In response to the transformation of China's economic in the middle-income stage, the following suggestions are proposed:

Firstly, in the middle-income stage, with the increase of the price of production factors, the original comparative advantage of China's manufacturing industry has gradually disappeared. New comparative advantages should be created through technological upgrading, and the level of China's participation in global industrial competition should be upgraded to new heights; Secondly, as far as the structure of the final product is concerned, China's current difficulties are mainly due to insufficient consumer demand and excessive reliance on investment. Therefore, the government must adjust the existing income distribution system, and avoid distortion of the final demand structure by fostering a stable consumer market; Finally, in the past more than 10 years, China has participated in the international division of labor in the way of processing trade. Although the economy has achieved rapid growth, it has consumed a lot of resources and is therefore unsustainable. In the new normal stage, with the change of economic growth mode and the rising of the position in the global value chain, there may be a phenomenon of decline in the speed of economic growth and a significant improvement in the quality of economic growth.

\section{Acknowledgements}

This paper is supported by National Social Science Foundation Project (14AZD085); National Natural Science Foundation of China (No.71573137); National Natural Science Foundation of China (No. 71373106).

\section{References}

[1] Solow, Robert M, 1957, "Technical change and the aggregate production function." The review of Economics and Statistics (1957): 312-320.

[2] Dong Minjie, Liang Yongmei, 2013: "The Source of China's Economic Growth from 1978 to 2010: A Nonparametric Decomposition Framework", Economic Research Journal, No. 5.

[3] Shen Lisheng, 2009: "Evaluation of Pulling Movements of Three Carriages", The Journal of Quantitative \& Technical Economics, No. 4. 
[4] Liu Ruixiang, An Tongliang, 2011: "The Power Source of China's Economic Growth and the Prospect of Transformation: An Analysis Based on the Final Demand", Economic Research Journal, No. 7.

[5] Pan Wenqing, 2012: "The Spatial Spillover Effect of China's Regional Association and Economic Growth", Economic Research Journal, No. 1.

[6] Li Jing, Chen Wei, Wan Guanghua, Fu Chenmei, 2014: "The Spatial linkageand Explanation of China's Regional Economic Growth and Its Explanation: Based on Network Analysis Method", Economic Research Journal, No. 11.

[7] Kuwamori, Hiroshi and Okamoto, Nobulllro, 2007“'Industrial Networks between China and the Countries of the Asia-Pacific Region”, IDE Discussion Paper, 2007, No. 110.
[8] Bo. Meng and Satoshi Inomata, "Production Networks and Spatial Economic Interdependence: An International Input Output Analysis of the Asia-Pacific Region", Discussion Papers, No. 185.

[9] Pan Wenqing, 2015: "China's Regional Economic Development: An Analysis Based on Spatial Spillover Effect", The Journal of World Economy, No. 7.

[10] Marcel P. Timmer, Abdul Azeez Erumban, Bart Los, Robert Stehrer and Gaaitzeh J. de Vries, 2014, "Slicing Up Global Value Chains", Journal of Economic Perspectives, Volume 28. Number 2. Pages 99-118.

[11] Zhi Wang, Shang-jin Wei, Xinding Yu and Kunfu Zhu, 2017, "Measures of Participation in Global Value Chains and Global Business Cycles", NBER working paper, No. 23222. 